\title{
Topic Study Group No. 40: Classroom Assessment for Mathematics Learning
}

\author{
Denisse R. Thompson, Karin Brodie, Leonora Diaz Moreno, \\ Nathalie Sayac and Stanislaw Schukajlow
}

\section{The Programme}

Prior to the conference, members of the two topic study groups on assessment (TSG 39 on Large Scale Assessment and TSG 40 on Classroom Assessment) collaborated to develop a topical survey on Assessment in Mathematics Education (Suurtamm et al., 2016). The survey addressed five main issues related to the current state of assessment:

- Purposes, traditions, and principles of mathematics assessment

- Design of assessment tasks in mathematics education

- Mathematics classroom assessment in action

- Interactions of large-scale and classroom assessment in mathematics education

- Enhancing sound mathematics assessment knowledge and practices.

Twelve papers were presented in the four main sessions of TSG 40, with the third session held jointly with TSG 39: Large-Scale Assessment and Testing in Mathematics Education. In addition, twelve papers were presented in the oral communication sessions and fourteen posters were also presented. Papers addressed topics related to all but the first issue in the pre-conference topical survey. The focus of the main topic study group sessions is indicated below.

Co-chairs: Denisse R. Thompson, Karin Brodie.

Team members: Leonora Diaz Moreno, Nathalie Sayac, Stanislaw Schukajlow.

\author{
D.R. Thompson $(\bowtie)$ \\ University of South Florida, Tampa, USA \\ e-mail: denisse@usf.edu \\ K. Brodie \\ University of Witswatersrand, Johannesburg, South Africa \\ e-mail: karin.brodie@wits.ac.za \\ (C) The Author(s) 2017 \\ G. Kaiser (ed.), Proceedings of the 13th International Congress on Mathematical \\ Education, ICME-13 Monographs, DOI 10.1007/978-3-319-62597-3_67
}


Session 1 included three papers focusing on assessment tools used by teachers, with three different models to assess student learning. Swan and Foster focused on design approaches to formative assessment with tasks developed that incorporate pre-assessment activities, formative feedback questions, and sample work for students to critique. Sia and Lim approached assessment for learning by developing a cognitive model for the concept of time and identifying attributes describing the knowledge and skills needed to answer tasks related to that concept; by associating the attributes with items and then finding students' patterns of success with the attributes, teachers have detailed feedback to make inferences to enhance student progress. Krieger, Platz, Winter, and Niehaus focused on the use of the open source web application, Internet Mathematics Assessment System (IMathAS), to help students in writing proofs; building the system for a proof requires identifying segments or phrases that would be appropriate as well as an acceptable sequence so that grading can be semi-automatic.

- Swan, M., \& Foster, C. Formative assessment lessons for concept development and problem solving.

- Sia, C. J. L., \& Lim, C. S. Using cognitive diagnostic assessments (CDA) as an alternative mode of assessment for learning.

- Krieger, M., Platz, M., Winter, K., \& Niehaus, E. Classroom assessment and learning support for logical reasoning in mathematics education-suggestion of an e-proof environment.

Session 2 included four papers focusing on teacher judgments and teacher learnings that occur as part of their assessment process. Sayac collected assessment tasks from primary teachers of varying experience levels and then analyzed the tasks for the level of complexity and nature of the competencies; she found most tasks were low level on both complexity and competency level. Hardie researched the sources that New Zealand teachers reference in making overall teacher judgments about student progress for parents or to document teaching and learning; teachers tended to use formal and informal methods in assessing their students' progress and had to learn to be skilled users of evidence from various assessment methods. Marynowski provided results from a case study of two secondary teachers in which she investigated both their beliefs about assessment as well as their actual practices, including students' perceptions of their teachers' practices; she found that neither teacher fully recognized how various practices related to their beliefs. In the final paper from this group, Pai described the beginning analysis of a phenomenological study investigating three phases of an ephemeral assessment cycle, namely eliciting, interpreting, and acting; he also explored factors that influence these phases.

- Sayac, N. How are pupils in French primary school assessed in mathematics? A didactical approach to explore this question.

- Hardie, C. P. Making overall teacher judgments in mathematics. 
- Marynowski, R. M. Secondary mathematics teacher assessment beliefs and practices.

- Pai, J. In-the-moment decisions: A preliminary investigation on observations and conversations as assessment in secondary mathematics classrooms.

Session 3 was held jointly with TSG 39, with a focus on psychometric models and other issues at the boundary of classroom and large-scale assessment. Two papers from TSG 40 were presented in this session. Bostic and Sondergeld described a process by which they developed and validated measures for assessing problem-solving ability of middle grades students, including linking of performance between the seventh and eighth-grade measures using Rasch IRT analysis. Ariza-Hernández, Rodríguez-Vásquez, and Arciga-Alejandre focused on assessing undergraduates' understanding of real functions of real variables using Sierpinska's four categories of understanding, namely identification, discrimination, generalization, and synthesis; students' achievement was analyzed using Bayesian IRT analysis to determine which categories of understanding students had achieved.

- Bostic, J. D., \& Sondergeld, T. Validating and vertically equating problemsolving measures.

- Ariza-Hernández, F. J., Rodríguez-Vásquez, F. M., \& Arciga-Alejandre, M. P. Analysis of the understanding of a mathematical concept using a Bayesian IRT model.

The three papers presented in the final session focused in some way on aspects of self-assessment within the mathematics classroom. O'Shea described assessment for learning through student autonomy, describing actions by an expert teacher to develop an environment in which grade 5 children engaged in critical dialogue to take control of their own learning. Veldhuis, van den Heuvel-Panhuizen, and Zhao compared the effects in the Netherlands and China of professional development support for teachers around issues of assessment on their students' achievement; teachers in the two countries varied in the length of time they participated in the professional development, with resultant differential effects on students' achievement. Straumberger described the use of self-diagnosis sheets as a means to help students assess confidence at using various competencies, and relating achievement to the accuracy of their self-diagnosis.

- O'Shea, A. Exemplifying the expert primary mathematics classroom: The case of Alex and assessment for learning.

- Veldhuis, M., van den Heuvel-Panhuizen, M., \& Zhao, X. Supporting primary teachers' assessment practice in mathematics: Effects on student learning in the Netherlands and Nanjing, China.

- Straumberger, W. Using self-assessment for individual practice in math classes.

Three short papers were presented in each of the four oral communication sessions, with the focus of the sessions providing an opportunity to expand on issues raised during the regular topic study group sessions. Most papers focused on issues related to formative assessment, including the design of tasks, use of rubrics, 
specific formative assessment strategies, or the use of digital or electronic environments to create tasks. In addition, various papers provided cultural perspectives on the use of formative assessment in different countries.

The papers in the topic study group sessions and oral communications, as well as the poster presentations, indicate that assessment at the classroom level is a pressing issue around the globe. Teachers and researchers are engaged in collaborative efforts investigating assessment for learning as well as assessment as learning, all in the service of enhancing mathematics learning of all students. The various papers also indicate that much work remains to be done within the overall assessment sphere as the mathematics education community attempts to better understand the interplay of teachers' assessment practices and students' learning.

Authors of several of the papers, oral communications, and posters will be expanding their contributions as part of a post-monograph publication related to the work of the TSG.

\section{Reference}

Suurtamm, C., Thompson, D. R., Kim, R. Y., Moreno, L. D., Sayac, N., Schukajlow, S., et al. (2016). Assessment in mathematics education: Large-scale assessment and classroom assessment (ICME-13 Topical Surveys). SpringerOpen.

Open Access Except where otherwise noted, this chapter is licensed under a Creative Commons Attribution 4.0 International License. To view a copy of this license, visit http://creativecommons. org/licenses/by/4.0/.

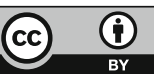

